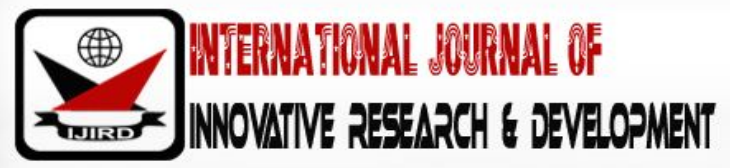

ISSN 2278 - 0211 (Online)

\section{Coping Mechanisms of Nursing Students in Clinical Placement}

Dorcas Frempomaa Agyare
Assistant Lecturer, School of Nursing, University of Cape Coast, Ghana
Isabella Garti
Faculty of Science, Department of Nursing, Valley View University, Ghana
Aw ube Menlah
Faculty of Science, Department of Nursing, Valley View University, Ghana
Yaa Boahemaa Gyasi
Assistant Lecturer, School of Nursing, University of Cape Coast, Ghana

Abstract:

Although clinical placement takes place in a clinical environment, the clinical environment presents many challenges to the nursing students on placement. This requires that nursing students have the ability to develop appropriate copying mechanisms in mitigating such challenges. However, for many nursing students, the ability to successfully cope in a clinical environment has been very challenging. Against this background, this study explored the coping mechanisms of nursing students in clinical placement at the School of Nursing and Midwifery, University of Cape Coast. Theoretically, the arguments of this paper are grounded in the transactional theory of coping which proves a typology of the interplay between stressors, the environment, psychosocial resources, and coping strategies on event outcomes. The descriptive survey design was employed through the administration of questionnaires to 132 nursing students. The Statistical Products and Service Solutions (SPSS), version 20 was used to analyse the data using both descriptive and inferential statistics. The study portrays a lack of sufficient support services to nursing students during clinical placements, and that the placement environment was generally unsupportive, making it difficult for students to cope. As such, several coping mechanisms were employed by the students during their placement. Major among them is seeking support from peers, creating a healthy relationship with nursing staff and avoiding the clinical environment. Nursing students on clinical placement should be sufficiently equipped with proper coping strategies in the placement environment, while management of the Nursing School should regularly visit students on placement to obtain relevant information about their progress and challenges.

Keywords: Coping, placement, clinical environment

\section{Background of the Study}

Like many other professional courses, nursing education generally comprises of theory and professional practice. Globally, the World Health Organization (2009) requires that for nursing education, theoretical training should at least represent one-third, while that of clinical practice should be at least one-half. It is crucial in health care for student nurses to acquire the relevant skills needed to become professional nurses in order not to endanger the safety of patients. However, Maben, Latter and Macleod (2006) argue that for many nursing students, the ability to integrate theoretical training in the clinical environment has been challenging. As a result, clinical field placement has formed an integral component in the curriculum of nursing education in many universities and nursing colleges. Effective nursing policies and programmes that can significantly influence the successful completion of clinical placement among nursing students are relevant in improving the clinical environment.

Contextually, a clinical environment includes everything that surrounds the nursing work, including the clinical settings, student supervision by clinical instructors, the use of clinical equipment, patients' relations, peer support, and student satisfaction (Barnett, 2012). For the purpose of this study, clinical placement is conceptualised as a medical facility where learning opportunities are available for nursing students to undertake practice in a clinical environment under supervision. It is therefore obvious that clinical placement takes place in the clinical environment, since it is in such environment that students meet real clinical situations. Such placement develops the clinical and interpersonal skills of nursing students, which are essential to providing quality health care. In this study, clinical environments are acute adult 
hospitals in the Cape Coast Metropolis, where nursing students have direct contact with patients, their relatives and the medical team.

An important factor affecting the teaching-learning process in a clinical setting is exposure to the clinical learning environment (Jamshidi, Molazem, Sharif, Torabizadeh \& Kalyani, 2016). Nursing students learn effectively in clinical environments that promote learning by encouraging and supporting and, making them feel a part of the medical team. Therefore, if the clinical environment is volatile, unstructured and devastating, nursing students can be left with feelings of vulnerability and anxiety. This, according to Flott and Linden (2015), consequently influences their self-confidence and readiness to practice as nurses, which ultimately has negative implications for quality health care.

Nursing students need to know about the clinical situations they will face and what is expected of them in the clinical environment. Important challenges nursing students encounter during clinical placement include role and goal ambiguity, power and discrimination relationships between students and their practice assessors, less clinical experience, fewer acquired coping skills, minimal power in the clinical environment's structure and are unfamiliar with the clinical environment and its standards among others. The challenges of the clinical environment require that nursing students have the ability to develop appropriate copying mechanisms in mitigating such challenges.

At the University of Cape Coast, School of Nursing and Midwifery, nursing students are required to undertake mandatory clinical courses on placement (Clinical Nursing Practice: 1, 2, 3, 4). However, available statistics from the School shows that many students are struggling to carry out their roles and responsibilities effectively during clinical placements, resulting in the majority averagely passing placement. However, a search of the literature shows that there seems to be no study on the coping mechanisms nursing students of the School of Nursing and Midwifery, employ during clinical placement to improve the clinical environment. Thus, there is less empirical evidence on the factors influencing the coping strategies of nursing students on clinical placement in the School of Nursing and Midwifery, University of Cape Coast as well as the expectations of students from the clinical environment. This gap in knowledge presents a priority for research in this paper.

\subsection{Objectives of the Study}

Evidence from literature (Ip \& Chan, 2005; Sharif \&Masoumi 2005; Kelly, 2007; Longley et al. 2007) suggests that there is a gap in integrating theory to practice in nursing education. This seems to affect student learning in clinical environment due to the abysmal passes in placement among students. Against this background, the purpose of the study is to examine the coping mechanisms of nursing students on clinical placement at the School of Nursing and Midwifery, and the implications for improving the clinical environment. Specifically, the study seeks to:

- $\quad$ Assess the supports available to nursing students during clinical placement;

- Evaluate the challenges nursing students encounter during clinical placement

- Examine the coping strategies nursing students employ during clinical placement;

- Explore effective means of enhancing the copying mechanisms of nursing students during clinical placement

\subsection{Hypothesis}

- $\quad \mathrm{H}_{1}$ : Availability of support service to students will significantly differ across gender and age

- $\mathrm{H}_{2}$ : Availability of support service to students will significantly differ across academic

- $\mathrm{H}_{3}$ : The coping strategies of the students will significantly address the challenges of the clinical environment

\subsection{Significance of the Study}

The findings from this study will have several implications for policy formulation and enhancement of the decisionmaking process to promote nursing practice. The findings will impact on the following stakeholders in the following ways:

- Nursing students: The findings from this study are essential in providing the basis for appropriate interventions by nursing students to improve their performance in the clinical environment. This is relevant to enable the development of a more reality-based integrated inter-professional coordination management framework to meet the total clinical needs of nursing students on placement. Thus, the implications of this study for nursing students is to lead to the development of student placement management strategies to revitalize placement education, sensitization, mobilization and motivation for students as well as the redirection, strengthening and provision of placement information

- University of Cape Coast: The findings of the study will also inform policy formulation for the School of Nursing and Midwifery in the University in relation to developing a guideline that can help build a harmonious inter- disciplinary and inter-professional partnership during clinical placement. This guideline will provide relevant information on how students can work with professionals from different professional backgrounds

- $\quad$ On the academic front, the study will add to the existing literature on nursing education placement management literature by providing knowledge base data that will cover institutional responsibility. Thus, the outcome of the study will advance the frontier of knowledge and add to the existing academic literature on the coping strategies nursing students employ in a clinical environment to effectively execute their roles and responsibility during placement. This will generate useful data that will prompt further research into the subject 


\subsection{Scope of the Study}

Although both graduate and undergraduate nursing students are required to undertake clinical placement, for the purpose of this study, focus was placed on undergraduate students. This was informed by the fact that most graduates nursing students are practicing nurses, familiar with the challenges in the clinical environment, hence have been able to develop some appropriate coping mechanisms. This, according to Morris and Blaney (2010) cannot be said of undergraduate students who are new to the clinical environment and its associated challenges.

\section{Literature Review}

Generally, the literature is reviewed from the theoretical, conceptual and empirical perspectives. Although a number of different theoretical positions can contribute to an understanding of coping mechanisms of nursing students on clinical placement, the transactional theory of coping forms the theoretical framework under which the arguments of this study are grounded. The theory was propounded by Lazarus (1966) and serves as a framework for evaluating the processes of coping with stressful events such as that in a clinical environment. Fundamentally, according to the theory, a transaction between a person and his/ her environment is stressful only when it is evaluated by the person as harmful, threatening, or challenging to the person's well-being (Greenblum, 2010). Conceptually, Glanz et al. (2002) define coping as the cognitive and behavioural efforts to manage specific external and internal demands that are appraised as taxing or exceeding the resources of a person. In other words, coping is a process used to manage demands that are thought to be threatening because they exceed the individual's resources (Lazarus \& Folkman, 1984). Therefore, when individuals appraise an event or situation as stressful, they must then cope with it.

Contextually, a nursing student on clinical placement would evaluate the clinical environment as demanding only when the environment is perceived as challenging (non-supportive and non-collaborative). This makes the concept of coping relevant in the clinical environment. Coping in the clinical environment will require constant changing of cognitive and behavioural efforts to manage the demands and resources of the environment. This requires different actions based on different stressors. The key constructs of the theory involve primary and secondary appraisals. According to Newness (2011), primary appraisal is a person's judgment about the significance of an event as stressful, positive, controllable, challenging or irrelevant. Secondary appraisal comes in when a stressor is encountered. The secondary appraisal is an assessment of a people's coping resources and options. However, the literature is unclear on the level of dependency of the primary and secondary appraisals, though there is overlapping of the primary and secondary appraisals (they are interdependent) as argued by Folkaman (2008).

Nursing students, who perceive the clinical environment as non-challenging and non- threating are more likely to show active coping skills and use avoidant coping strategies, or strategies that ignore the presence of the stressor (Stoeber \& Renner, 2008). Therefore, balancing the demands of the clinical environment with the provision of the relevant resources nursing student needs to deal with such demands is essential for their success in the clinical setting. However, Glanz et al. (2008) argue that actively trying to change the situation and alter the stressor, instead of perceiving it as stressful, could be the most beneficial coping approach for nursing students on clinical placement. Although one of the major objectives in clinical placement is to achieve effective integration of theory with practice, the reality, for many nursing students is that this is poorly done in most clinical environment (Marsh \& Triseliotis, 1996). Learning in clinical settings creates challenges which are absent in the classroom. This is explained by Papp et al. (2003) argument that the clinical learning environment is not easy to control due to the many stimuli, making it difficult for the nursing students to discern what is essential. This tends to frustrate and stressed students during their clinical placement (Awuah-Peasah, 2013).

There are several challenges for students in the clinical environment. The student supervisor relationship can either serve as a threat or an opportunity to the success of clinical placement. Generally, warm, supportive, and interested field instructors contributed in aiding their students to deal with the experience and continue in their studies (Strozier, BarnettQueen \& Bennett, 2000). Therefore, the absence of a potentially helpful supervisor appears to exacerbate students' negative reactions. However, Baum (2007) indicates that field supervisors needed more support on coping with relationships with their students, and more education on the termination / endings of placements. The lack of contextual knowledge of the external supervisor into the medical facility could impact nursing students' placement, supervision and assessment. Zuchowski (2015) notes the difficulties in assessing students' performance and providing feedback to them without seeing their actual practice.

Generally, school supervision visits offer opportunities for nursing students and medical facility supervisors to get guidance in pursuing the objectives of the clinical placement and also to assess student performance. However, Dhemba (2012) argues that such visits have been inconsistent. In other words, failure by university supervisors to assess nursing students on clinical placement can have a very damaging effect on their morale, the medical facility supervisor and the clinical placement in general. This obviously diminishes the importance of clinical placement and also undermines the learning process. Aside this, Kaphagawani and Useh (2013) observe that the lack of supervision may lead nursing students learning incorrect procedures. Similarly, Yastik et al. (2011) observe that lack of supervision results in negative experiences in the clinical environment which affect students' attitudes and confidence in the environment. This could be detrimental to the lives of their patients. This requires universities to make resources available through budgetary allocation for placement coordinators. Learning in clinical practice takes place if students are made aware of what they are doing right or wrong at the 
clinical environment from their clinical instructors and university supervisors through feedback. However, Clynes and Raftery (2008) observes that due to lack of supervision, such feedbacks are not given to nursing students on clinical placement. Feedbacks help students to gain confidence since it helps them to know their progress in the clinical environment.

The concept of quality is central to the nursing profession, of which establishing minimum quality requirement is challenging (Finch, 2010). The lack of standardization across medical facilities on the relevant competences for qualified nursing practices has also resulted in student placement failure rats. McGregor (2013) notes that majority of nursing students on clinical placement are required to carry out works that should be conducted by qualified nurses. In some instances, clinical instructors often expected nursing students to be experts, despite their inexperience and lack of knowledge, while in few instances; nursing students are given unsupervised responsibilities for one or more cases during their first practice placement. This contradicts with the Global Nursing Code of Practice. Lack of effective communication between university authorities and the clinical instructors also contribute to the negative experiences of the student nurses, particularly during clinical placement (Rikhotso, 2014). Due to the lack of effective communication, Mabuda (2008) observes that clinical instructors could not understand the learning objectives of student nurses.

Empirically, Mek (2011) explored nursing students' learning experiences during their clinical rotations, with a focus on stress, anxiety and coping at the Concordia University Montreal, Quebec, Canada. Despite different perceptions, the participants felt that communication and the development of relationships with nurses and medical staff was difficult and stressful. Yildiz and Akansel (2011) explored nursing students' experiences of being allocated to a cancer ward for the first placement and identified the main challenges experienced in Turkey. Students' initial placement experiences were stressful and, although students reported trying to prepare psychologically before starting their placement, they experienced anxiety (which diminished over time); worry about caring for severely ill patients; not knowing how to communicate effectively with the cancer patients; and observing negative practices related to patient care and treatment. Msiska (2012) also explored the clinical learning experience of Malawian undergraduate student nurses in the Kamuzu College of Nursing (KCN). The study reveals that clinical learning experience is enormously challenging and portrays lack of support to students during clinical placements. In some clinical settings, the psychosocial atmosphere appears oppressive and hostile and sometimes students are shouted at. Absenteeism and abscondment are some of the distancing or detachment strategies which students employ when allocated in such clinical settings in order to protect their emotions. Khater et al. (2014) explored the sources of stress and coping behaviours in clinical practice among baccalaureate nursing students in Jordan, using a coping behaviour inventory (CBI) scale. The study concludes that nursing students agonise about assignments and grades and might inhibit positive clinical learning experiences. Alshahrani (2015) examined the factors assisting undergraduate nursing students of the University of Adelaide, Australia to cope with the experience of their first clinical placement. The study population was first year undergraduate bachelor of nursing students. The participants had a positive first clinical placement experience due to several factors. Key among them are preparation, debriefing, support and good communication. Nursing staff in clinical institutions were also positive and supportive of nursing students.

In conclusion, the finding of these studies illustrated that nursing students are not equipped with proper coping strategies to deal with clinical stress that inherent in their clinical experiences. In other words, current review revealed that students coping experiences in clinical placement had received inadequate attention. Additionally, the challenges nursing students encounter during clinical placement are both internal and external, and that the several challenges do not sufficiently expose them to the nursing practice. However, there is limited knowledge on the contribution of the personal circumstances of the nursing students including family and health conditions to clinical placement challenges. Largely, identifying challenges of nursing students in the clinical learning environment could improve training and enhance the quality of its planning and promotion of the students.

\section{Methodology}

To ensure that the relevant data is collected and analysed accurately in accordance with the research questions, the descriptive survey design was employed. The design has the potential to provide a lot of information regarding the coping strategies from quite a large sample of nursing students within a short period (Creswell, 2002). Specifically, quantitative data was obtained through the administration of questionnaires to undergraduate nursing students on clinical placement in the School of Nursing and Midwifery. In sampling, the population of nursing students on clinical placement was divided into four homogenous cohorts using the academic level as the basis for the stratification. After the stratification, students in each cohort were selected using simple random sampling. The sample size for the study was determined using the Slovin Formula (Umar, 2000):

$$
n=\quad \frac{N}{1+N(e)^{2}} \quad \ldots 1 \quad \text { Wheren= sample size, } \mathrm{N}=\text { population size (number of nursing students on clinical }
$$

placement), $\mathrm{e}=$ significance level in percentage of error that is allowed is seven percent

The content of the questionnaire was developed based on the literature review in relation to the objectives of the study. A modified version of the Coping Behaviour Inventory (CBI) questionnaire created by Sheu et al. (2002) which has predominantly been used to study coping experience of nursing students was adopted for the study. The questionnaire was pre-tested in determining its reliability. The quantitative data was coded and entered using the Statistical Product and Service 
Solutions (SPSS), version 20 involved the generation of descriptive and inferential statistics. In testing the hypotheses, in statistical terms: if

p-value $>0.05 \Rightarrow$ Reject $\mathrm{H}_{1}$ at 0.05 , p-value $\leq 0.05=>$ Do Not Reject $\mathrm{H}_{1}$ at 0.05

\section{Results}

\subsection{Demographic Characteristics}

Available statistics from the School of Nursing and Midwifery shows that there are currently 450 undergraduate students on clinical placement in the University. From the sample size calculation, 140 students were expected to participate in the study. However, of the 140 administered questionnaires, 132 were returned giving a response rate of 94.3 percent. More than half $(n=77,58.3 \%)$ of the respondents were females while over 80 percent $(n=113,85.6 \%)$ were aged 20-30 years. Regarding academic level, $40.2 \%(n=53), 33.3 \%(n=44)$ and $26.5 \%(n=35)$ of the respondents were respectively in level 400,300 and 200.

\subsection{Support Available to Nursing Students on Clinical Placement}

The majority $(63.2 \%, n=84)$ affirmed that there are support services for students on clinical placement. However, the proportion that indicated otherwise (no support services) was equally high $(36.8 \%, n=48)$. Figure 4.1 shows the specific support services available to the students during clinical placement.

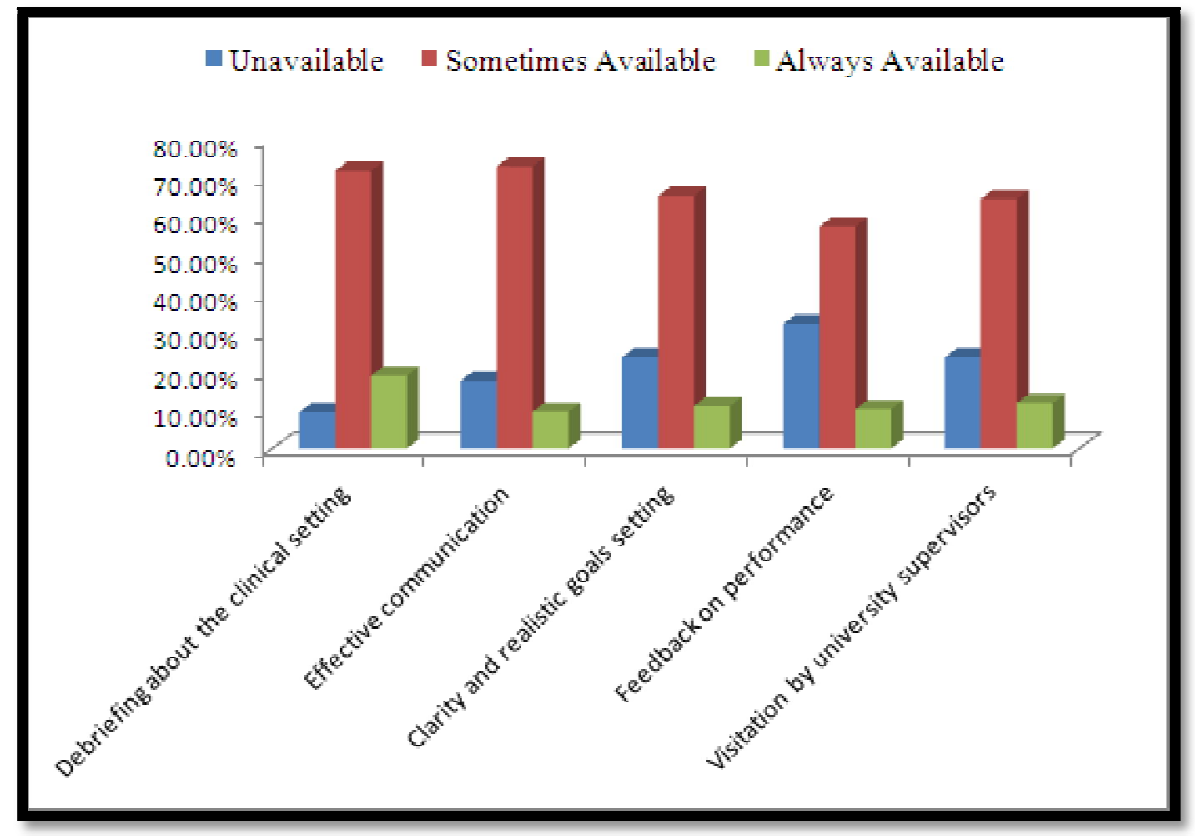

Figure 1: Support Services Availability

Source: Administered Questionnaire (2017)

In Figure 1, majority (71.9\%) of the students noted that the hospital management sometimes debrief them about the clinical setting and that they are sometimes effective communication from hospital management (73.0\%). A little over 60 percent (65.4\%) indicated that they are sometimes given clear and realistic goals and get visitation by university supervisors/ clinical instructors (64.6\%).

\subsubsection{Hypothesis Testing}

- $\mathrm{H}_{1}$ : Availability of support service to students will not significantly differ across gender and age

- $\mathrm{H}_{2}$ : Availability of support service to students will not significantly differ across academic

\begin{tabular}{|c|c|c|c|}
\hline Variables & Chi-Square $\left.\mathbf{( X}^{\mathbf{2}}\right)$ & Df & P-Value \\
\hline Age & 3.921 & 2 & 0.141 \\
\hline Gender & 4.627 & 1 & 0.031 \\
\hline Level & 2.415 & 3 & 0.491 \\
\hline
\end{tabular}

Table 1: Hypothesis Testing Using the Chi-Square Test

Source: Administered Questionnaire (2017) 
In Table 1, it is seen that with the exemption of gender $((\mathrm{p}<0.005)$, the availability of support services during clinical placement did not significantly differ ( $p>0.005)$ across age and academic level. Of the 77 females, $54(70.1 \%)$ were of the view that there are support services. Also, of the 55 males, 29 (50.9\%) indicated same. In other words, the proportion of females that perceived the availability of support services in the clinical environment is less than that of the males. Though the availability of support services is not significantly different across the academic levels of the students, the level of support diminishes as the students' levels increases. While 70.0 percent of the students in level 200 indicated that there are support services, 64.0 percent of those in level 300 and 56.1 percent of those in level 400 respectively indicated same.

\subsection{Challenges Nursing Students on Clinical Placement Encounter}

More than half $(54.6 \%)$ of the students affirmed that the clinical environment is somehow challenging while 37.9 percent rated the environment as very challenging. Thus, less than 10 percent rated the environment as not challenging (7.5\%). The essential areas of the clinical environment where the students feel very challenging were also analysed using the weighted mean $(\mu)$ :

Weighted Mean $(\mu)=\frac{\sum \mathrm{w}}{\mathrm{N}}$.

Where $\mathrm{w}$ is the weighting given to each factor by the respondents, ranging from 1 to 5 , and $\mathrm{N}$ is the total number of respondents (132).

\begin{tabular}{|c|c|c|c|c|c|c|}
\hline \multicolumn{9}{|c|}{ Weights } \\
\hline Area & 1 & 2 & 3 & 4 & 5 & Total \\
\hline Familiarity & 37 & 30 & 35 & 23 & 7 & 132 \\
\hline Supervision & 14 & 29 & 41 & 22 & 26 & 132 \\
\hline Equipment & 14 & 32 & 33 & 34 & 19 & 132 \\
\hline Patients relations & 40 & 41 & 30 & 14 & 7 & 132 \\
\hline Peer relations & 56 & 36 & 26 & 7 & 7 & 132 \\
\hline
\end{tabular}

Table 2: Weighting of Challenging Areas of the Clinical Environment

Source: Administered Questionnaire (2017)

Using the weights in Table 2, the weighted mean and the rankings are shown in Table 3. A higher weighted mean suggests the most challenging area.

\begin{tabular}{|c|c|c|}
\hline Variables & Weighted Mean $(\boldsymbol{\mu})$ & Ranks \\
\hline Familiarity & 2.5 & 3 \\
\hline Supervision & 3.5 & 5 \\
\hline Clinical equipment & 3.1 & 4 \\
\hline Patients relations & 2.3 & 2 \\
\hline Peer relations & 2.0 & 1 \\
\hline
\end{tabular}

Table 3: Ranking of Challenging Areas of the Clinical Environment

Supervision by clinical instructors was rated as the most challenging area for the students in the clinical environment $(\mu=3.5)$. The use of clinical equipment was ranked by the students as the second most challenging area of the clinical environment $(\mu=3.1)$. Familiarity with the clinical environment was ranked as the third essential challenge in the clinical environment $(\mu=2.5)$ while Patients $(\mu=2.3)$ and peer relations $(\mu=2.0)$ were ranked as the least essential areas of the clinical environment the students are challenged.

\subsection{Coping Strategies of Nursing Students in the Clinical Environment}

The specific coping mechanisms used by the students in the clinical environmental were also analysed of which the results are shown in Figure 1. 


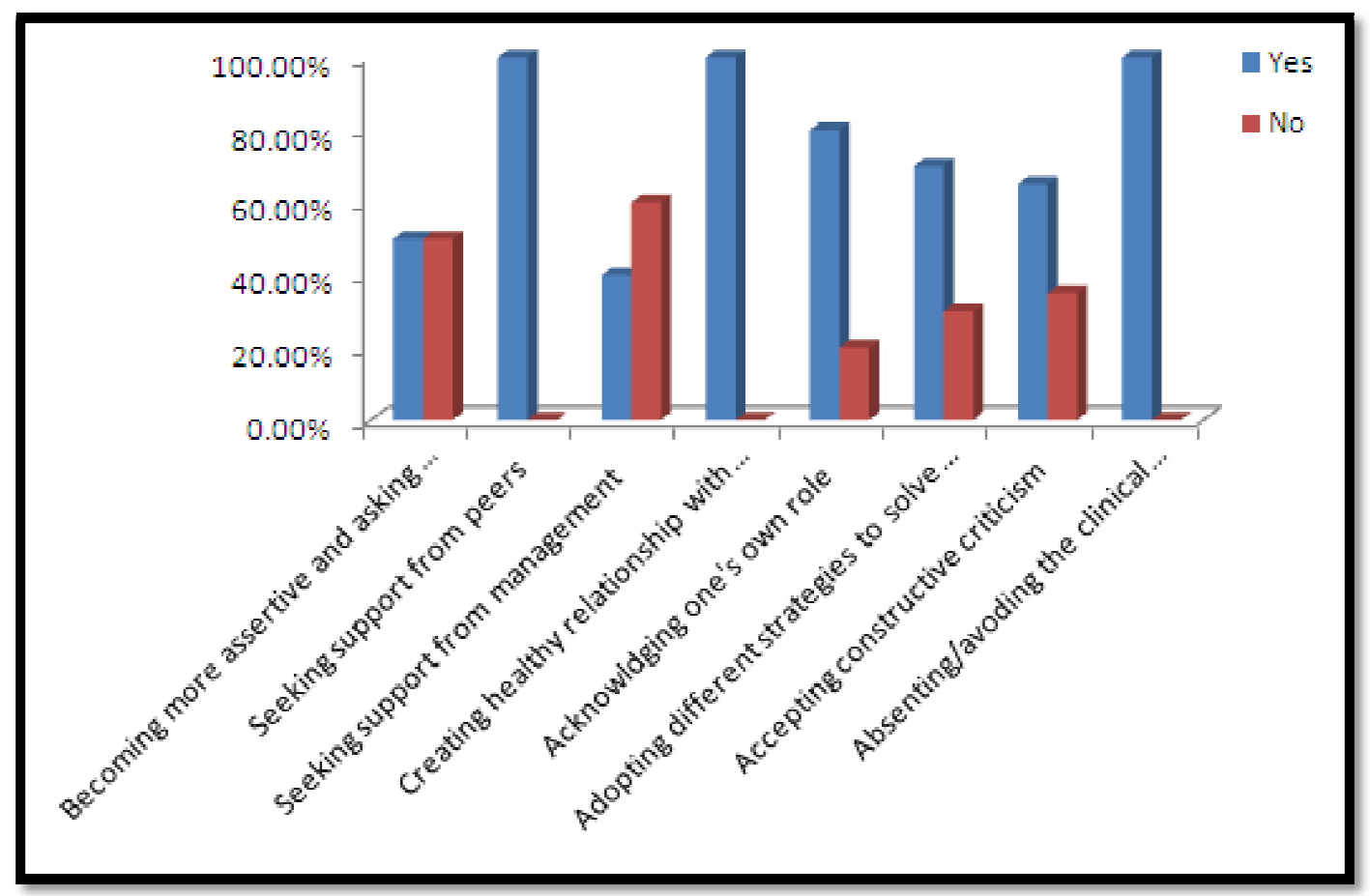

Figure 2: Coping Strategies Used by Students on Clinical Placement Source: Administered Questionnaire (2017)

All the respondents (100.0\%) indicated that seeking support from their peers, creating a healthy relationship with nursing staff and avoiding the clinical environment are the mechanisms used to cope with the challenges of the clinical environment.

The study further analysed the significance of the coping strategies employed by the students in addressing the challenges of the clinical environment using the ordinal regression analysis. Pseudo R-Square analysis presented a Nagelkerke value of 0.973 which implies that 97.3 percent of the variation in the coping strategies was explained by the challenging nature of the clinical environment. Table 4 shows the regression model fitting information.

\begin{tabular}{|l|l|l|l|l|}
\hline Model & -2 Log Likelihood & Chi-square & df & Sig \\
\hline Intercept only & 167.915 & & & \\
\hline Final & 0.000 & 167.915 & 56 & 0.000 \\
\hline \multicolumn{5}{|c|}{ Table 4: Model Summary } \\
Predictors: Coping Strategies, P Is Significant at 0.05 \\
Source: Administered Questionnaire (2017)
\end{tabular}

As part of testing the significance of the ordered logistic regression analysis, the significance of the model that includes the predictor variables which has been arrived through an iterative process that maximises the log likelihood of the outcomes seen in the outcome variable was performed. It is noted that the regression model is significant $\left(\chi^{2}=167.915, p=0\right.$. 000) as shown in Table 4 and that

\section{Discussion}

The proportion of females that participated in the study was 16.6 percent more than that of the males. This was expected considering the fact that the nursing profession has historically been perceived as female-dominated one (Agyemang-Dankwah, 2015). However, there are also increasing numbers of males joining the profession in recent time. Generally, the students were young and youthful.

According to Chesser-Smythe (2005), support services provided to students on clinical placement could affect their sense of belongingness and subsequently increased their anxiety, capacity and motivation to learn the profession. However, having over 30 percent (36.8\%) of the respondents not receiving any support services in the clinical environment could affect their sense of belongingness in the clinical environment, and de-motivate them to learn the clinical profession. This is against Maben, Latter and Macleod (2006) argument that for most nursing students, the ability to integrate theoretical training in the clinical environment has been challenging. The support services are inadequate to help students cope well with the pressures within the clinical placement. However, considering the argument of Ip and Chan (2005) that clinical placement takes place in a dynamic social complex environment, it is essential that sufficient support services are provided to students. 
There were generally no well-organized induction programmes for the students in the clinical environment. This is worrisome considering Dellasega (2009) observation that nursing students are particularly vulnerable when entering the clinical environment, hence the need to offer proper orientation. More than 70 percent of the respondents indicating that there are sometimes effective communications from hospital management is positive considering Robbins et al. (2010) assertion that during clinical placement, managers need to give orders, assign tasks, provide instructions and directions, and inform students of job procedures and policies, through communication. While an effective supervision is supposed to be bi-directional between the supervisor and the students, the supervisors do not regularly monitor the progress of the students. This supports Dhemba (2012) argument that such visits have been inconsistent.

The majority (54.6\%) of the respondents rated the clinical environment as somehow challenging while 37.9 percent rated it as very challenging. This means that coping in the multi-functional team has not been easy for many nursing students on placement. The results support Morris and Blaney (2010) that the clinical environment presents many challenges to the nursing students on placement. This is explained by Dellasega (2009) observation that nursing students often have less clinical experience and fewer acquired coping skills. Supervision by clinical instructors was rated as the most challenging area for the students in the clinical environment. Such experiences according to Chesser-Smythe (2005) could affect the students' sense of belongingness and subsequently increased their anxiety, capacity and motivation to learn the profession. According to Godden (2012), for supervision to be effective, it needs to combine a performance management approach with a dynamic, empowering and enabling supervisory relationship. From this and the findings presented, it is clear that the students have not had an effective clinical instructor supervisory experience. This is worrisome, considering Hawkins and Shohet (2006) assertion that supervision is very important in a profession like the nursing profession which handles mostly emotions. The use of clinical equipment was ranked by the students as the second most challenging area of the clinical environment. This was not surprising since hospital equipment are sophisticated, complex and require specifications for their use. However, the findings are consistent with Dellasega (2009) argument that nursing students have less clinical experience including experience with hospital equipment. Patients being ranked as the least essential areas the students are challenged imply that students have developed their own supporting and coping mechanisms for supporting each other.

All the respondents (100.0\%) indicated that seeking support from their peers, creating a healthy relationship with nursing staff and avoiding the clinical environment are the mechanisms used to cope with the challenges of the clinical environment. These are consistent with Melling (2011) assertion that building relationships enabled students to gain access to opportunities to develop their nursing skills as they gained access to learning opportunities to enable them to develop their skills through social conversation. Though all the students tried to build and maintain a positive relationship with other nursing staff in the clinical environment as a coping strategy, the development of such relationships was difficult for most of the students.

\section{Recommendations}

Though support services are provided to students on clinical placement, these services are inadequate and are sometimes non-available. The most available of these services is the debriefing about the clinical setting by the hospital management. Generally, coping in the placement environment had not been easy for many of the students due to the very challenging nature of the clinical environment. Thus, the clinical environment has been very demanding for the students. Major among the coping strategies employed by the students is seeking support from peers, creating a healthy relationship with nursing staff and avoiding the clinical environment.

Considering the multi-faceted nature of most nursing placement, and the inherent challenging experiences, effective theoretical and practical training should be offered to students to equip them in this regard. They should be taught how to develop facilitation skills as a mechanism for coping during the clinical placement. Thus, management of the School of Nursing and Midwifery should focus on balancing the demands of the clinical environment with the provision of the relevant supports nursing student needs to deal with such demands. Lack of effective communication between university authorities and the placement instructors have also resulted in the non-supportive nature of the clinical environment. As such, placement instructors could not understand the learning objectives of student on placement. To enhance the communication, management of the School of Nursing and Midwifery, University of Cape Coast should regularly visit students on clinical placement to obtain relevant information about their progress, and challenges. The School of Nursing and Midwifery in the University of Cape Coast should champion a strong re-integration and promotion of relationship-based practice into modern day nursing curriculum. Considering therapeutic development forming a component of the nursing profession, academic institutions should seek to promote quality (dynamics) of the working relationships students on placement build with their working staff. Therefore, for nursing students to be able to demonstrate the skills and qualities needed to create an active partnership with other professions in the clinical environment, the current curriculum should demonstrate a sound theoretical and practical understanding of the importance of building and maintaining good relationships and, more importantly, the ability to use this knowledge in practice.

There is the need for all stakeholders in the placement process to harmonise and synchronise their activities to enhance coordination. However, effective coordination begins with communication. A coordination forum should be formed to ensure that a strategy for the full integration of placement student and other professional teams is implemented. The formation of the forum should start by simply compiling a database of all the stakeholders in the hospitals in which nursing 
placements are taken. The fundamental goal of the clinical placement is to bridge the gap between theory and practice in nursing education. Therefore, the management of the Hospital should ensure that they give appropriate feedback to the students based on their performances. This may be done in writing or verbal to enable the students track their progress during clinical placement. Also, management need to device ways of communicating effectively with the students. In this era of technology, social media could be employed; phones calls, emails, and bulk text messages are all media that may be employed to improve on their communication. Based on the key findings emanated from this study, a further research should be conducted to determine the failure rate of students undertaking clinical placement. There are clear indications that many of the students struggle to be successful in their clinical placement.

\section{References}

i. AlShahrani, Y. M. (2015). Factors that assist undergraduate nursing students to cope with the experience of their first clinical placement (Doctoral dissertation).

ii. Awuah-Peasah, D. (2013). The attitudes of student nurses toward clinical work. International Journal of Nursing and Midwifery, 5(2), 22-27.

iii. Barnett, R. (2012). Clinical education: perceived abilities/ qualities of clinical educators and team supervision of students. Physiotherapy. 89 (7), 432-440.

iv. Baum, N. (2007). Field supervisors' feelings and concerns at the termination of the supervisory relationship. The British Journal of Social Work, 37(6), 1095-1112,

v. Clynes, M. P., \& Raftery, S. E. (2008). Feedback. An essential element of student learning in clinical practice. Nurse Education in Practice, 18: 405-411

vi. Creswell,J. W. (2002). Research design qualitative, quantitative and mixed methods approach. $\quad$ London: Sage Publications.

vii. Dellasega, C.A. (2009). Bullying among nurses. American Journal of Nursing, 109(1), 52-58.

viii. Dhemba, J. (2012). Fieldwork in social work education and training: issues and challenges in the case of Eastern and Southern Africa. Social Work \& Society, 10(1).

ix. Finch, J. L. (2010). Can't fail, won't fail-why practice assessors find it difficult to fail social work students: a qualitative study of practice assessors' experiences of assessing marginal or failing social work students (Doctoral dissertation, University of Sussex).

x. Flott, E.A. \& Linden, L. (2015). The clinical learning environment in nursing education: a concept analysis. J Adv Nurs, 72(3), 501-513

xi. Folkaman, S. (2008). The case for positive emotions in the stress process. Anxiety, Stress, and Coping, 21(1), 3-14.

xii. Glanz, K., Rimer, B. K., \& Lewis, F. M. (2002). Health behaviour and health education. San Francisco, CA: Jossey-Bass

xiii. Greenblum, C. M. (2010). Women in perimenopause and menopause: Stress, coping and quality of life (Doctoral dissertation, University of Florida).

xiv. Ip, W. Y., \& Chan, D. S. (2005). Hong Kong Nursing students' perception of the clinicalenvironment: A questionnaire survey. International Journal of Nursing Studies, 42, 665-672.

xv. Jamshidi, N., Molazem, Z., Sharif, F., Torabizadeh, C., \& Kalyani, M. N. (2016). The challenges of nursing students in the clinical learning environment: A qualitative study. The Scientific World Journal, 1-7

xvi. Kaphagawani, N. C., \& Useh, U. (2013). Analysis of nursing students learning experiences in clinical practice: Literature review. Ethno Med, 7(3), 181-185.

xvii. Khater, W., Akhu-Zaheya, L., \& Shaban, I. (2014). Sources of stress and coping behaviours in clinical practice among baccalaureate nursing students. International Journal of Humanities and Social Science, 4(6), 194-202.

xviii. Lazarus, R. S. (1966). Psychological stress and the coping process.

xix. Lazarus, R. S., \& Folkman, S. (1984). Stress, appraisal and coping. NY: Springer Publishing Company.

xx. Maxim, P. S. (1999). Qualitative research, methods in the social science. New York: Oxford University Press.

xxi. Maben, J., Latter, S., \& Macleod, C. J. (2006). Theory-practice gap. Impact of professional bureaucratic work conflict on newly qualified nurses. Journal of Advanced Nursing, $\quad 55,465-477$.

xxii. Mabuda, B. T. (2008). Student nurses' experiences during clinical practice in the Limpopo Province. Curationis, 31(1), 19-27.

xxiii. McGregor, K. (2013). Social workers more likely to turn to food than to managers as way of Coping with stress. Community Care, 2.

xxiv. Mek, M. (2011). Nursing students' learning experiences in clinical settings: Stress, anxiety and coping (Doctoral dissertation, Concordia University).

xxv. Morris, C., \& Blaney, D. (2010). Work-based learning. West Sussex: Wiley-Blackwell.

xxvi. Msiska, G. (2012). Exploring the clinical learning experience: Voices of Malawian undergraduate student nurses

xxvii. Papp, I., Markkanen, M., \& Bonsdorff, M. (2003). Clinical environment as learning environment: Student nurses' perceptions concerning clinical experiences. Nurse Education Today, 23(4), 262-268.

xxviii. Sharif, F. \& Masoumi, S. (2005). A qualitative study of nursing student experiences of clinical practice. BMC Nurs, 4, 1-7. 
xxix. Sheu, S., Lin, H. S., \& Hwang, S. L. (2002). Perceived stress and physio-psycho-social status of nursing students during their initial period of clinical practice: The effect of coping behaviors. International Journal of Nursing Studies, 39(2), $165-175$.

xxx. Stoeber, J., \& Rennert, D. (2008). Perfectionism in school teachers: Relations with stress appraisals, coping styles, and burnout. Anxiety, stress, and coping, 21(1), 37-53.

xxxi. Strozier, A. L., Barnett-Queen, T., \& Bennett, C. K. (2000). Supervision: Critical process and outcome variables. The Clinical Supervisor, 19(1), 21-39.

xxxii. Rikhotso, R. (2014). 'Some mix it with other things to smoke': Perceived use and misuse of ARV by street thugs in Tshwane District, South Africa.

xxxiii. Yildiz, H., \& Akansel, N. (2011). Beginning level nursing students' experiences with cancer patients in their first clinical placement: a qualitative appraisal in Turkey. Asian Pacific Journal of Cancer Prevention, 12(10), 2611-2615.

xxxiv. Umar, S. E. (2000). Slovin's formula sampling techniques. Norton: Demand Media Inc. 